\title{
Intermetallic phase kinetic formation and thermal crack development in galvanized DCI
}

\author{
Costanzo Bellini, Francesco Carlino \\ University of Cassino and Southern Lazio, Italy \\ costan₹o.bellini@unicas.it, http://orcid.org/0000-0003-4804-6588 \\ francesco.carlino@unicas.it
}

\begin{abstract}
A new class of material characterized by mechanical properties close to the traditional low and medium carbon steel is the Ductile Cast Irons (DCIs). High castability and low production costs allow them to be used in many fields, ranging from automotive to piping. In this class of iron-based alloy the content of carbon is mainly localized in the graphite nodules, which are dispersed in a metallic matrix characterized by different phases: ferrite, austenite, pearlite, martensite or their mix, depending on the chemical composition and the heat treatment. Metallic matrix is subjected to the corrosion phenomenon, and, for this reason, the study and the development of traditional and innovative protection techniques are important, mainly in critical applications. Hot dip galvanizing is one of the investigated protections because the zinc is able to protect the iron-based alloys thanks to the reduction potential that is lower than the iron one.

In this work, a ferritic-pearlitic DCI (GS500) is galvanized by using a pure Zn bath at $440^{\circ} \mathrm{C}$ in order to generate a zinc coating at different dipping time. The presence of thermal cracks is observed by means of a Scanning Electron Microscope (SEM).
\end{abstract}

KeYwords. Hot Dip Galvanizing; Ductile Cast Iron; Damage; Stress field.

\section{INTRODUCTION}

$\mathrm{H}$ ot Dip Galvanizing (HDG) is today the most important processing technique used to protect metallic materials in many aggressive environments, thanks to the low production costs of protective coatings and the ability of zinc to protect the metallic substrate against the hostile surroundings [1-3]. The zinc-based coatings protect the metallic coated substrate by a double effect:

- A barrier effect, that is able to separate the external environment to the alloy to be protected;

- An electrochemical protection due to the low electrochemical potential of zinc. 
The protection action of HDG coating can protect the substrate also in the presence of short cracks which eliminate the barrier effect. In this case, the galvanic couple between zinc and iron is able to protect the substrate allowing corrosion of the zinc coating. The corrosion product of zinc, characterized by white colour, is often able to repair the crack generating a new barrier.

The formation of the coating is governed by both physical and chemical parameters. Some physical parameters are bath temperature, immersion time, pre-galvanizing surface temperature, etc. Main controlling chemical parameters are the steel and the bath chemical compositions, flux chemical composition, and so on.

The formation of hot dip galvanizing coatings is due to interdiffusion of zinc and iron atoms between zinc-based melting and iron-based specimens dipped in the bath. Due to different chemical composition, the interdiffusion of atoms generates a non-uniform coating characterized by different intermetallic phases. In the rich zinc zone (close to the surface of coating) the presence of a $\eta$ phase is due to the wettability of melting zinc and the chemical composition is very close to the chemical composition of the bath. Towards the inner zone the content of iron increases, generating a different zinc-based phase characterized by a columnar morphology $\zeta$ phase). This phase is due to the interdiffusion phenomena between iron and zinc atoms in the radial direction, which is the direction of coating growth, and it can lose the columnar morphology if the coating will be exposed at high temperature for a long time. It happens for instance, at high dipping time, where the secondary diffusion phenomena (not only in the radial direction but also in transversal direction) takes place. The $\zeta$ phase is characterized by a monoclinic unit cell and an atomic structure that contains a Fe atom and a $\mathrm{Zn}$ atom surrounded by $12 \mathrm{Zn}$ atoms at the vertices of a slightly distorted icosahedron. The icosahedra link together to form chains and the linked chains pack together in a hexagonal array [4].

Increasing the content of iron, a new phase is observed in the inner zone of the coating. This phase is often named as $\delta$ phase. It is a brittle one, with Fe content up to $11.5 \mathrm{wt} \%$ and characterized by a hexagonal crystal structure.

Finally, for higher Fe contents a presence of another brittle phase, often named as $\Gamma$, could be observed, but it is characterized by a very thin layer, sometimes with a thickness of about a few atoms. The $\Gamma$ phase is characterized by Fe content up to $29 \mathrm{wt} \%$ and by an FCC structure.

Hot dip galvanizing processes are very important in order to control the properties of coatings.

In the galvanized steel strip, an innovative HDG process is able to control the thickness of an adherent coating film by impinging a thin plane nitrogen gas jet. This technique has been adopted in some continuous hot-dip galvanizing process [5].

Presence of different alloy elements in the bath allows to optimize the HDG processes in order to reduce the scraps but it permits also to change the traditional intermetallic phases, for instance improving the corrosion resistance and the mechanical properties [7]. For instance, stable reaction products that allow improving corrosion resistance have been observed on electrochemically passivated HDG surface [4-6]. Other authors analysed the influence of alloy elements in terms of microstructural phases compositions [8]. As observed by Shibli (2006), the presence of silicon in the coated steel strongly influences coatings formation and their properties. The mechanisms of silicon interaction with galvanizing reactions can be summarizing as follows (Figure 1) [8]:

- Galvanizing reactions move Fe $\alpha$ toward $\Gamma$ phase;

- Silicon does not move toward $\Gamma$ phase because its solubility in $\Gamma$ is very low. As consequence silicon increases its contents at $\mathrm{Fe} \alpha-\Gamma$ interface;

- $\quad \alpha$-Fe, rich in silicon, breaks the interface, and particles enter in the $\delta$ phase;

- Particles dissolving in the $\delta$ phase increases the thickness.

In order to improve the coatings performances, it is possible to introduce different techniques also in pre-galvanizing phase [9]. For example, traditional pre-galvanizing treatment can be optimized by replacing conventional flux by using vegetable oil like the linseed oil or using mineral oil. The presence of mineral oil protects the substrate because is a sort of barrier against oxygen. Furthermore, the addition of hydrochloric acid in the oil leads to an improvement of coated areas and their adherence. Finally, the addition of natural fatty acid, used in the flux operation, leads to good galvanizations too, due to its light acidity as observed for the additions of hydrochloric acid [9].

The intermetallic phases growth and their performances are strongly influenced by the chemical composition of the bath. Addition of the strontium improves both the adhesive strength and the corrosion resistance of hot-dip galvanized coating [10]. The presence of $\mathrm{SiO} 2 \mathrm{Na} 2 \mathrm{O}$ molar ratio of silicate solution leads to a decrease in the corrosion rate, increasing both the polarization resistance and total impedance values [11].

Sometimes for improving the corrosion resistance of the zinc coating, or just for changing the colour of the galvanized surface, painting can be used. In order to improve the adhesion on the galvanized surface, an organofunctional silane deposition on hot-dip galvanized can be performed [12]. 


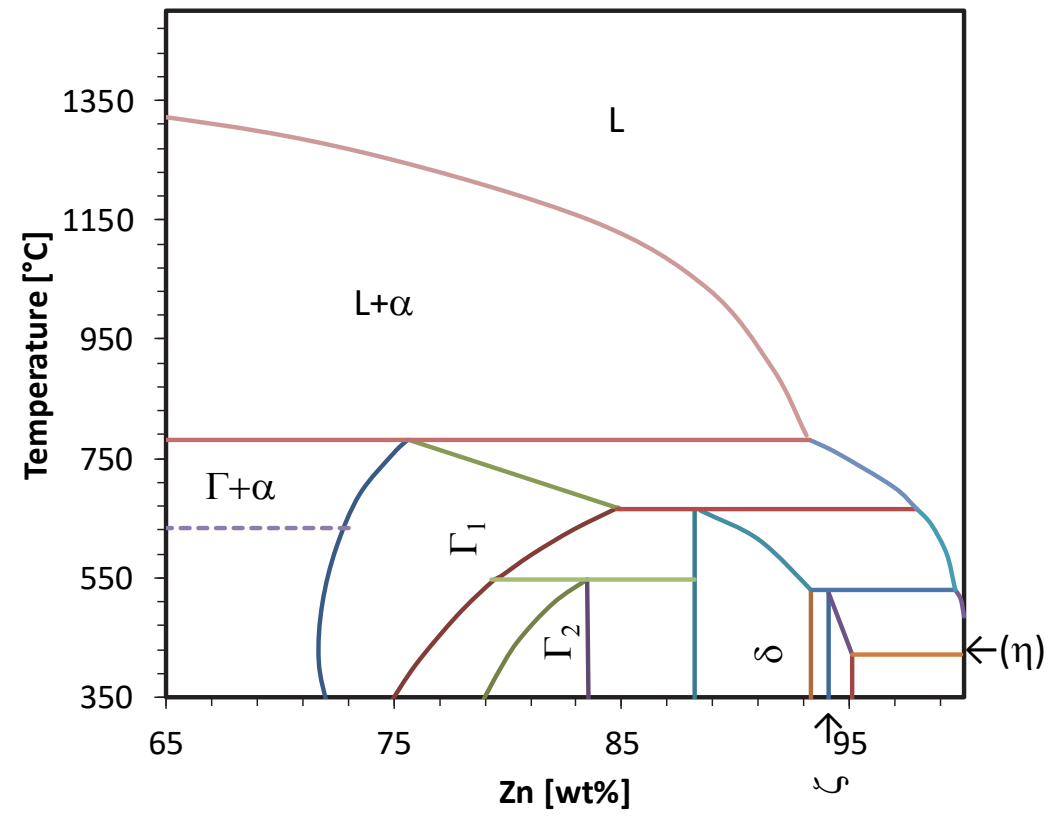

Figure 1: Section of phase diagram of zinc-iron [4].

In the past, the additions of $\mathrm{Pb}$ were used to fluidify the zinc bath, increasing also the $\Gamma$ layer thickness and improving the corrosion resistance [13]. Many processes were optimized for the $\mathrm{Pb}$ additions, but today the presence of $\mathrm{Pb}$ cannot be accepted due to recent laws. The main element that is usually considered as $\mathrm{Pb}$ substitute is the $\mathrm{Sn}$, but other metallic elements can be used leading to different intermetallic phases formations and different corrosion and mechanical performances.

More studies, oriented to the intermetallic phases damage, have been carried out [15-18] in order to better understand the behaviour of the intermetallic phases in tensile and in compression loads.

In the last years a new cheap class of cast irons, the Ductile Cast Irons (DCIs) became more and more interested in galvanizing protection [19]. This is due to the performances of DCIs which are characterized by mechanical properties similar to the medium and low carbon steels [20-24].

In this work, a commercial Ductile Cast Iron, the GS500, characterized by a ferritic-pearlitic matrix is investigated in order to evaluate the coating formation during different dipping time.

The kinetic of coating formation and the role of graphite nodules have been analysed by means of Light Optical Microscope (LOM) and Scanning Electron Microscope (SEM) observations. Presence of thermal cracks has been investigated too.

\section{MATERIAL AND METHODS}

$\mathrm{I}$

$\mathrm{n}$ this work a commercial GS500 ductile cast iron, characterized by a ferritic-pearlitic matrix is investigated in order to observe the kinetics of coating formations, taking into account the role of the graphite nodules. Then, galvanized specimens are used to perform bending tests in order to evaluate the damage of different intermetallic phases. The chemical composition of the GS500 used in the galvanizing operation is shown in Table 1.

\begin{tabular}{cccccccc}
\hline $\mathrm{C}$ & $\mathrm{Si}$ & $\mathrm{Mn}$ & $\mathrm{P}$ & $\mathrm{S}$ & $\mathrm{Cr}$ & $\mathrm{Sn}$ & $\mathrm{Fe}$ \\
3.65 & 2.72 & 0.18 & 0.03 & 0.010 & 0.05 & 0.035 & Bal. \\
\hline
\end{tabular}

Table 1: Chemical composition investigated DCI (wt \%) [19].

Rectangular flat specimens $80 \times 25 \times 3 \mathrm{~mm}$ are machined from a rolled bar of GS500 in order to obtain samples to be galvanized and immediately protected by using a wetting oil. In this case, no pickling operation is needed and the surfaces of specimens are not etched by any acid. Before galvanizing, the oil layer is removed by using soap solutions and rinsed with alcohol. Subsequently, the specimens are fluxed in an aqueous solution containing $280 \mathrm{~g} / 1 \mathrm{ZnCl} 2$ and $220 \mathrm{~g} / 1 \mathrm{NH} 4 \mathrm{Cl}$ 
at laboratory temperature for 2 minutes and then they are dried for 10 minutes at $100{ }^{\circ} \mathrm{C}$. After this procedure, they are immediately dipped into the galvanizing bath, at $440 \pm 2{ }^{\circ} \mathrm{C}$ for different time (respectively $15,60,180,360$ and 900 seconds) and cooled in air.

In order to identify the thermal damaging mechanisms for each investigated dipping duration, longitudinal sections of the bent specimens are metallographically prepared and observed by means of both an optical microscope (LOM) and a scanning electron microscope (SEM).

\section{COATING FORMATION KINETICS}

alvanized specimens are analysed by means a LOM with and without chemical etching in order to evaluate the role of graphite nodules during the coating formation (without etching) and the intermetallic phases formation kinetic (by nital 2\% etching for $60 \mathrm{~s}$ ).

Considering the observation of unetched coating sections (Figure 2) it is possible to underline that the presence of graphite nodules is observed also in the coating for each investigated dipping time [19].
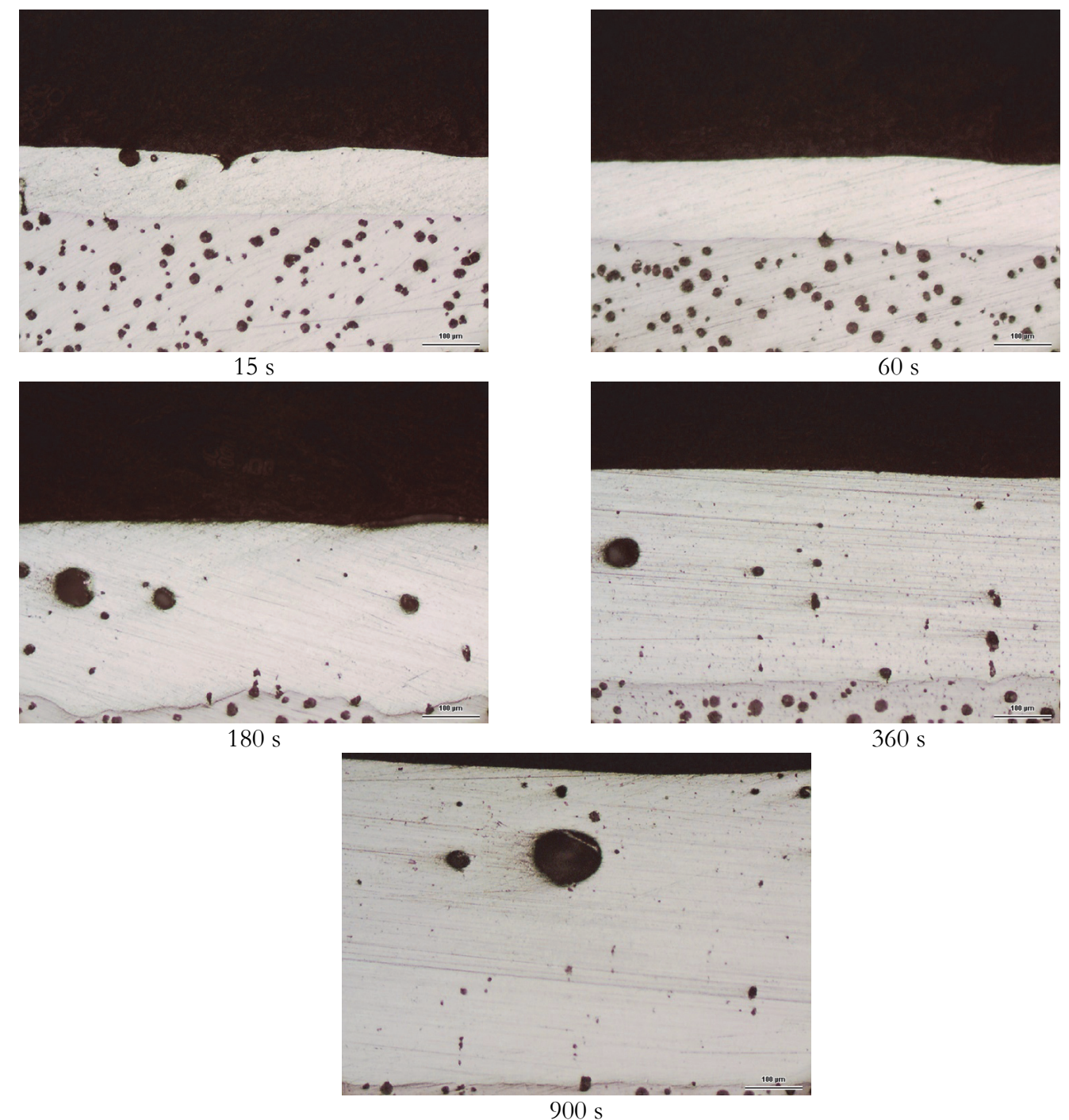

Figure 2: Unetched section of galvanized GS500 at different dipping time.

Starting from $180 \mathrm{~s}$ up to $900 \mathrm{~s}$, it is observed the presence of many dark round zones which can be the effect of carbon dispersed in the zinc. These zones can be the effect of coalescence of carbon and/or the effect of CO 2 or CO due to the high temperature interaction of graphite to the oxide dispersed in the bath. 
Considering all the unetched observations, the mean thickness of the coating can be measured for each one of the dipping times, and the values are shown in Figure 3.

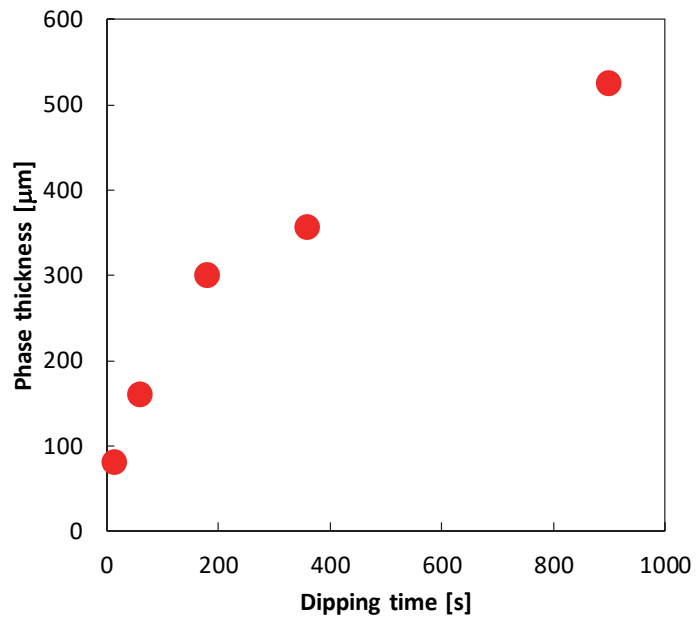

Figure 3: Coating thickness kinetics.

As shown in Figure 3, up to the dipping time of $360 \mathrm{~s}$ the kinetic formation of coating seems to be like the kinetic governed by interdiffusion phenomena, but for the higher investigated dipping time a sharp increase of thickness is observed. Furthermore, at $15 \mathrm{~s}$ of dipping time, the minimum measured thickness is about $80 \mu \mathrm{m}$. This value is very high if compared to the traditional steel galvanizing and it is due to the high presence of silicon in the GS500 which leads to high reactivity of galvanizing alloy in the $\mathrm{Zn}$ bath. Often, for $60 \mathrm{~s}$ of dipping time the thickness of the coating is about 30 $\mu \mathrm{m}$ in a commercial low carbon steel, that is more than two times lower. It means that the hot-dip galvanizing of DCIs is much more performing than the traditional steels both in terms of costs and in terms of time to galvanizing.

\section{INTERMETALLIC PHASES FORMATION KINETICS}

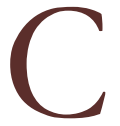

onsidering the etched section (Figure 4), all the traditional intermetallic phases which characterized the traditional Zn coatings are observed. In particular, the main phase seems to be the $\zeta$ for all investigated time conditions, and the $\eta$ phase seems to be negligible for higher dipping time.

Moreover, the $\delta$ phase seems to be present in all investigated dipping time.

In Figure 5, the kinetic formation of different intermetallic phases is shown, and the kinetic of $\zeta$ phases seems to be similar to the behaviour of the whole coatings shown in Figure 3. It means that the $\zeta$ phase is the main phase of the coatings generated in the DCI.

Furthermore, the presence of $\eta$ phases seems to be negligible for 15, 60 and $900 \mathrm{~s}$, whereas the $\delta$ phase thickness seems to be almost constant starting from 180s up to 900 s.

Finally, considering the presence of graphite in the coating, the presence of void is also observed in the coatings like the graphite in many different shapes. As shown in Figure 6, not all the dark zones are characterized by the graphitic carbon presence; for instance, as observed in the chemical elements maps, the dark area in the upper right zone of the Figure 6 is characterized by a presence of a low quantity of carbon. It could be due to the presence of desegregation of carbon of some graphite nodules in the coating.

\section{THERMAL AND GRAPHITE DAMAGE}

7 he formation of coating in investigated GS500 leads to a formation of a very damaged brittle $\delta$ phase as observed in the Figure 7, where the red arrows show the radial crack due to the thermal effect. These cracks are dominant, in terms of number of cracks, but are present only in the $\delta$ phase. No thermal cracks are observed in the $\zeta$ phase.

Furthermore, it is observed how the carbon of graphite tends to dissolute in the coating (nodules on the right of Figure 7). The upper side of this nodule seems to extend toward the radial direction. The new shape of the graphite tends to be like 
a lamella, as observed in the upper left zone of Figure 7. In terms of mechanical properties, the lamellar shape implies a decrease in performances.

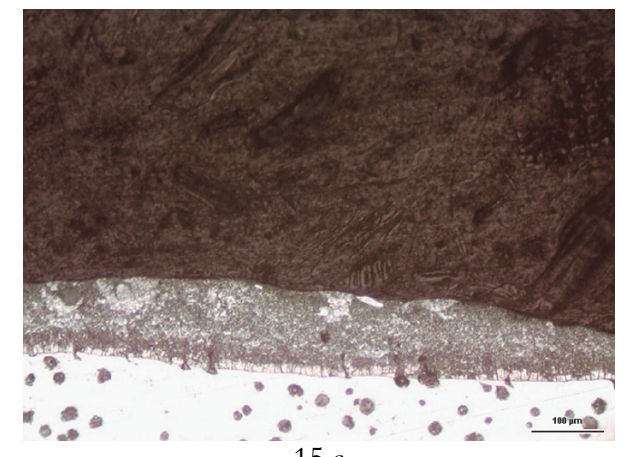

$15 \mathrm{~s}$

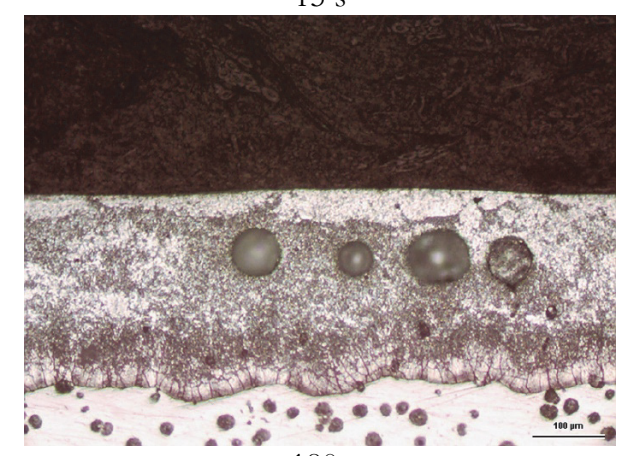

$180 \mathrm{~s}$
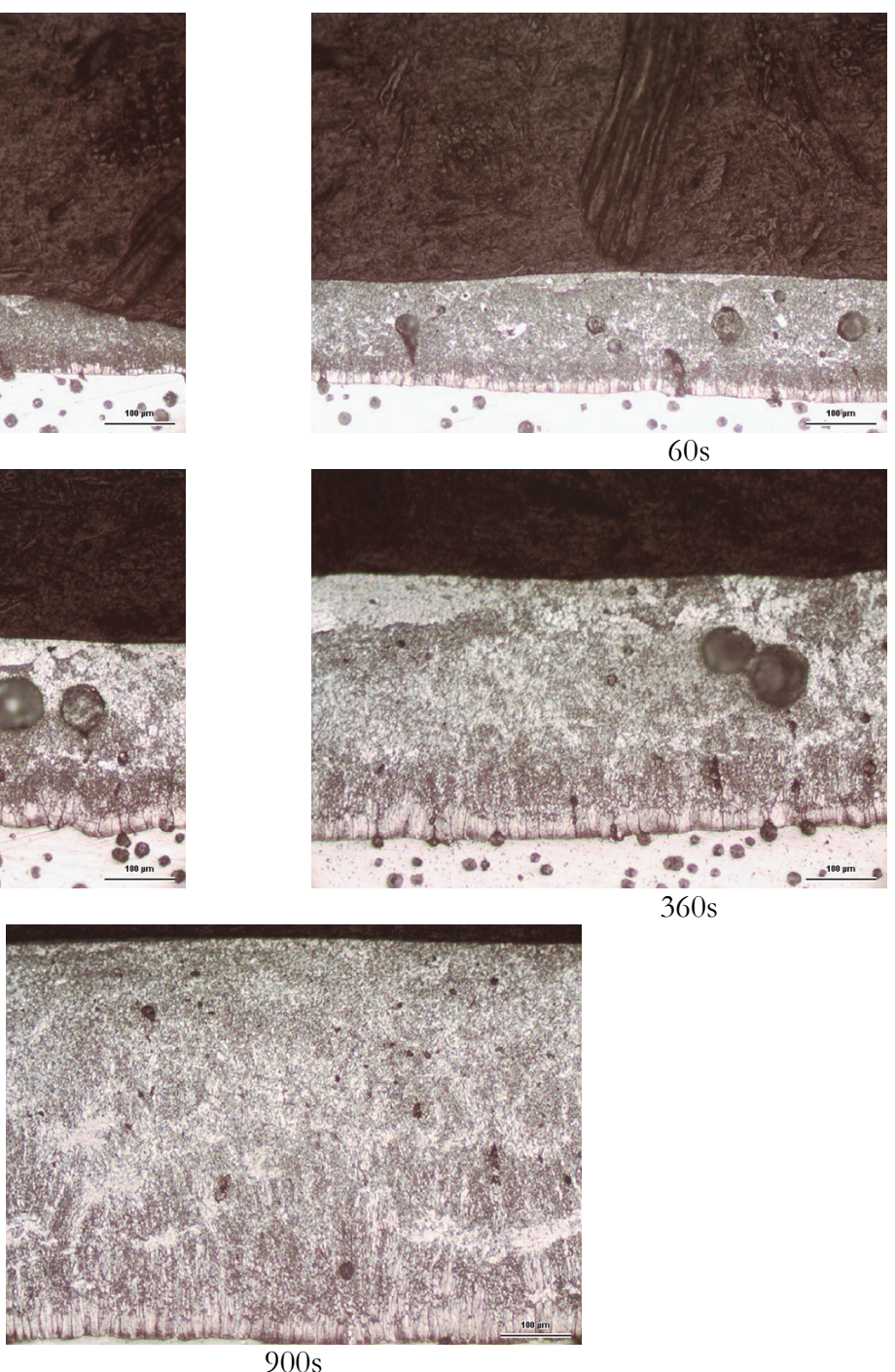

Figure 4: Etched section of coatings.

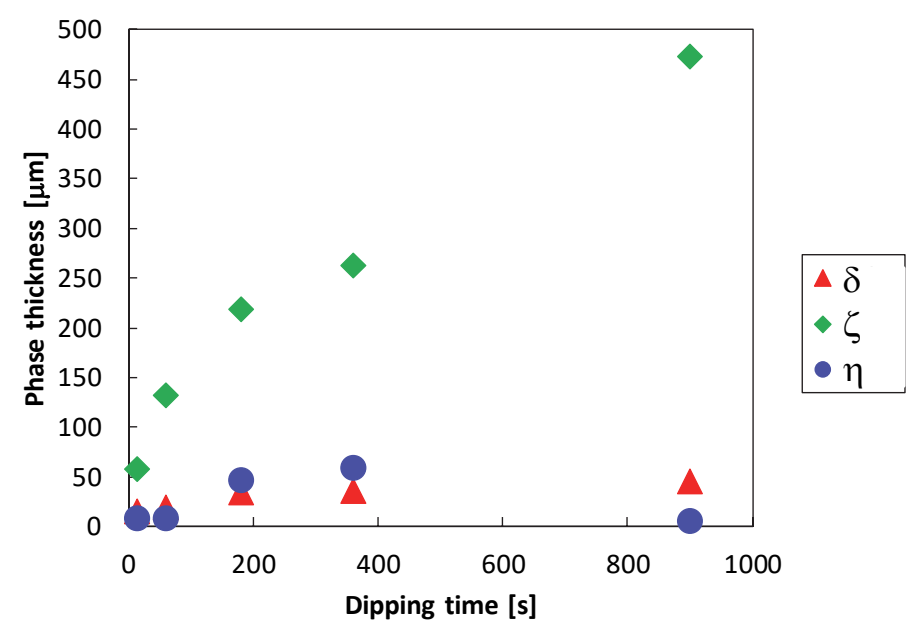

Figure 5: Intermetallic phases formation kinetics. 

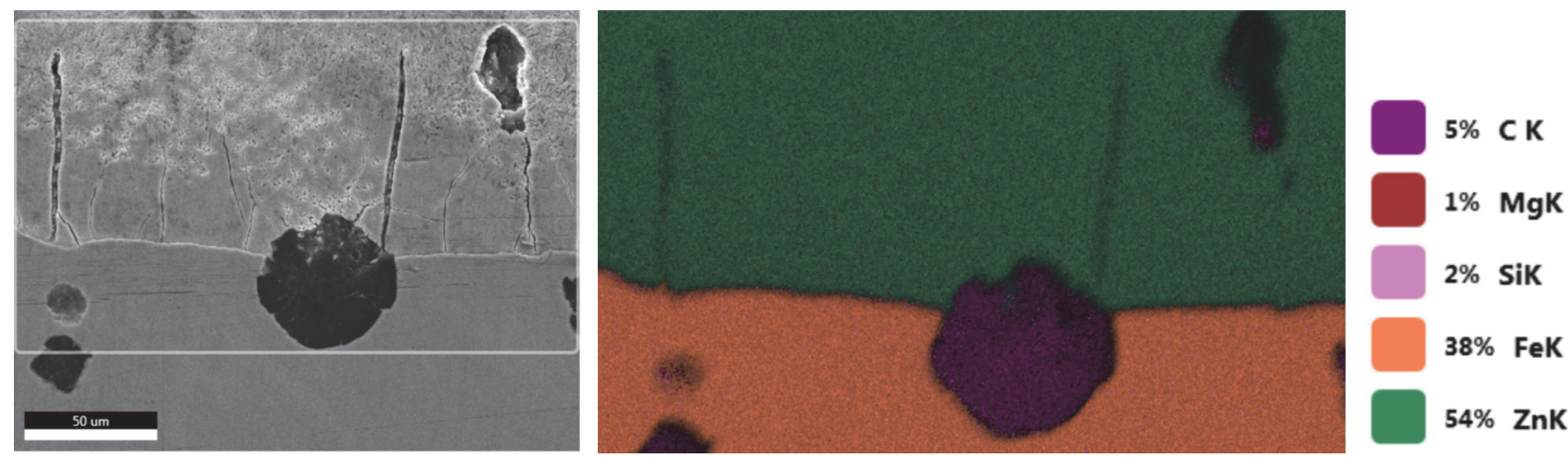

Figure 6: Mapping of the elements in the GS500-Coating interface.

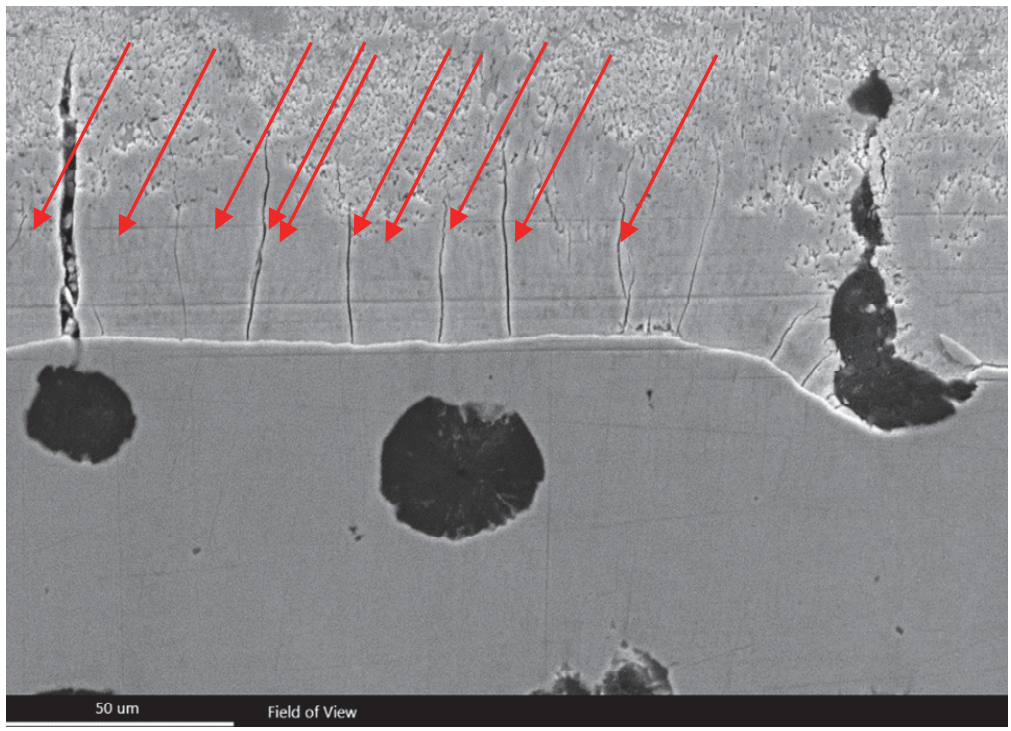

Figure 7: Thermal crack and graphite dissolution.

\section{CONCLUSION}

$\mathrm{I}$ $\mathrm{n}$ this work, a traditional DCI is used to investigate the kinetic formation of the intermetallic phases in coatings obtained by traditional $\mathrm{Zn}$ bath. The investigated dipping times $(15,60,180,360$ and $900 \mathrm{~s})$ are chosen in order to investigate the thicknesses of each intermetallic phase and of the whole coating, both at lower and at higher dipping time.

The results in terms of achieved thicknesses are very interesting. The minimum coating thickness is more than two times bigger than the thickness of steel coating in traditional dipping time $(60 \mathrm{~s})$. For all the investigated dipping times, the main phases observed is the $\zeta$ one, and mainly for the highest dipping time the $\eta$ phase is negligible.

The presence of graphite nodules in the DCI generates a sort of migration of nodules from the substrate to the coating. In many cases the graphite migrates without other phenomena, but in a few cases the graphite derogates generating voids or voids with low content of carbon.

The thermal damage observed is due to the brittle behaviour of the $\delta$ phase, but all the thermal cracks propagate in the $\delta$ toward the $\delta-\zeta$ interface that is a crack arresting.

\section{REFERENCES}

[1] Vitkova, St., Ivanova, V., Raichevsky, G. (1996). Electrodeposition of low tin content zinc-tin alloys, Surf. Coat. Tech., 82, pp. 226-231. DOI: 10.1016/0257-8972(95)02662-2. 
[2] Katiforis, N., Papadimitriou, G. (1996). Influence of copper, cadmium and tin additions in the galvanizing bath on the structure, thickness and cracking behaviour of the galvanized coatings, Surf. Coat. Tech., 78, pp. 185-195.

DOI: 10.1016/0257-8972(94)02408-1.

[3] Jintang, L., Chunshan, C., Gang, K., Qiaoyu, X., Jinhong, C. (2006). Influence of silicon on the $\alpha$-Fe/ $\Gamma$ interface of hot dip galvanized steels, Surf. Coat. Tech., 200, pp. 5277-5281. DOI: 10.1016/j.surfcoat.2005.06.017.

[4] Marder, A.R. (2000). A Review of the Metallurgy of Zinc Coated Steel, Prog. Mater. Sci., 45, pp. $191-271$. DOI: 10.1016/S0079-6425(98)00006-1.

[5] Yoon, H.G., AHN, G.J., Kim, S.J (2009). Aerodynamic investigation about the cause of check-mark stain on the galvanized steel surface, ISIJ Int., 49, pp. 1755-1761. DOI: 10.2355/isijinternational.49.1755.

[6] Singh, D.D.N. and Ghosh, R. (2008). Molybdenum-phosphorus compounds based passivator to control corrosion of hot dip galvanized coated rebars exposed in simulated concrete pore solution, Surf. Coat. Tech., 202, pp. 4687-4701. DOI: 10.1016/j.surfcoat.2008.03.038.

[7] Tzimas, E. and Papadimitrou, G. (2001). Cracking mechanisms in high temperature hot-dip galvanized coatings, Surf. Coat. Tech., 145, pp. 176-188. DOI: 10.1016/S0257-8972(01)01323-8.

[8] Shibli, S.M.A. and Manu, R. (2006). Development of zinc oxide-rich inner layers in hot-dip zinc coating for barrier protection, Surf. Coat. Tech., 201, pp. 2358-2363. DOI: 10.1016/j.surfcoat.2006.04.012

[9] Balloy, D., Dauphin, J.Y., Tissier, J.C. (2007). Study of the comportment of fatty acids and mineral oils on the surface of steel pieces during galvanization, Surf. Coat. Tech., 202, pp 479-485. DOI: 10.1016/j.surfcoat.2007.06.021.

[10] Vagge, S.T. and Raja, V.S. (2009). Influence of strontium on electrochemical corrosion behavior of hot-dip galvanized coating, Surf. Coat. Tech., 203, pp. 3092-3098. DOI: 10.1016/j.surfcoat.2009.03.026.

[11] Yuan, M.R., Lu, J.T., Kong, G. (2010). Effect of SiO2:Na2O molar ratio of sodium silicate on the corrosion resistance of silicate conversion coatings, Surf. Coat. Tech., 204, pp 1229-1235. DOI: 10.1016/j.surfcoat.2009.10.024.

[12] Bexell, U. and Grehlk, T.M. (2007). A corrosion study of hot-dip galvanized steel sheet pre-treated with $\gamma$ mercaptopropyltrimethoxysilane, Surf. Coat. Tech., 201, pp. 4734-4742. DOI: 10.1016/j.surfcoat.2006.10.014.

[13] Asgari, H., Toroghinejad, M.R., Golozar, M.A. (2008). The role of texture and microstructure in optimizing the corrosion behaviour of zinc hot-dip coated steel sheets, ISIJ Int., 48, pp. 628-633.

DOI: $10.2355 /$ isijinternational.48.628.

[14] Gallego, A., Gil, J.F., Castro, E., Piotrokowski, R. (2007). Identification of coating damage processes in corroded galvanized steel by acoustic emission wavelet analysis, Surf. Coat. Tech., 201, pp. 4743-4756. DOI: $10.1016 /$ j.surfcoat.2006.10.018

[15] Di Cocco, V. (2012). Sn and Ti influences on intermetallic phases damage in hot dip galvanizing, Fract. Struct. Int., 22, pp. 31-38, DOI: 10.3221/IGF-ESIS.22.05

[16] Di Cocco, V., Iacoviello, F., Natali, S. (2014). Damaging micromechanisms in hot-dip galvanizing Zn based coatings, Theor. Appl. Fract. Mec., 70, pp 91-98, DOI: 10.1016/j.tafmec.2014.05.003

[17] Vantadori, S., Carpinteri, A., Di Cocco, V., Fortese, G., Iacoviello, F., Natali, S., Ronchei, C., Scorza, D., Zanichelli, A. (2017). Novel zinc-based alloys used to improve the corrosion protection of metallic substrate, Eng. Fail. Anal., 82, pp. 327-329. DOI: 10.1016/j.engfailanal.2017.05.043

[18] Bellini, C., Iacoviello, F., Carlino, F., Di Cocco, V. (2019). The influence of hot dip galvanizing process on intermetallic phases formation, Mater. Des. Process. Commun., in press, DOI: 10.1002/mdp2.39.

[19] Di Cocco, V., Iacoviello, F., Carlino, F., Natali, S. (2018). Bending damages in galvanized ductile cast irons, Proc. Struct. Int., 9, pp. 265-271. DOI: 10.1016/j.prostr.2018.06.036

[20] Iacoviello, F., Di Cocco, V. (2016). Influence of the graphite elements morphology on the fatigue crack propagation mechanisms in a ferritic ductile cast iron, Eng. Fract. Mech., 167, pp. 248-258.

DOI: $10.1016 /$ j.engfracmech.2016.03.041.

[21] Di Cocco, V., Iacoviello, F., Rossi, A., Cavallini, M. (2014). Damaging micromechanisms characterization in a ferriticpearlitic ductile cast iron, Fract. Struct. Int., 30, pp. 62-67. DOI: 10.3221/IGF-ESIS.30.09.

[22] Iacoviello, F., Di Cocco, V., Rossi, A., Cavallini, M. (2013). Ductile cast iron: damaging micromechanisms at crack tip, Fract. Struct. Int., 25, pp. 102-108. DOI: 10.3221/IGF-ESIS.25.15.

[23] Iacoviello, F., Di Cocco, V., Cavallini, M. (2016). Fatigue crack propagation and overload damaging micromechanisms in a ferritic-pearlitic ductile cast iron, Fatigue Fract. Eng. Mater. Struct., 39(8), pp. 999-1011.

DOI: https://doi.org/10.1111/ffe.12443

[24] Iacoviello, F., Di Cocco, V., Bellini, C. (2019). Fatigue crack propagation and damaging micromechanisms in Ductile Cast Irons, Int. J. Fatigue, 124, pp. 48-54, DOI: 10.1016/j.ijfatigue.2019.02.030. 